\title{
Field instrumentation of a preloading project with prefabricated vertical drains
}

\author{
A Mehdizadeh Swinburne University of Technology, Australia \\ K Fakharian Amirkabir University of Technology, Iran
}

\begin{abstract}
Excessive consolidation settlements are always considered major threats for construction on soft soils. There are different methods to improve the soft cohesive sublayers. Preloading with vertical drains as one of the cheapest methods was selected for a ground improvement project in southwest of Iran near the Persian Gulf. The construction steps included soil instrumentation such as vibrating wire and Casagrande piezometers, magnetic extensometer, surface settlement monument, inclinometer, installation of prefabricated vertical drains (PVDs) and placement of embankment as a surcharge to accelerate the consolidation time for construction of two water tanks with a total volume of $100,000 \mathrm{~m}^{3}$. The length and spacing of PVDs for both water tanks were 15 and $1.5 \mathrm{~m}$, respectively. This paper presents and compares instrumentation results in different soil layers for both water tanks and investigates the effects of loading rate and its consequences. In addition, back-analyses were carried out using the hyperbolic and Asaoka methods, on the basis of which some recommendations are provided for the instrument installation in soil layers and result interpretations. The findings demonstrate that the instrumentation is an indispensable part of preloading projects, owing to difficulties of evaluating the smear zone effects, design parameters and unpredicted problems during the project progress. Service time of PVDs and instruments, especially piezometers, must be considered for required time of consolidation and the Asaoka method predicts maximum settlements better than the hyperbolic method for this project.
\end{abstract}

\section{Introduction}

Consolidation of soft clay deposits takes many years owing to low hydraulic conductivity of clay structure. The induced excess pore pressures (EPP) corresponding to applied loads dissipate very slowly and soil cannot experience the effective stresses immediately. Preloading is one of the most reliable and cheapest ground improvement methods accelerating the consolidation time.

Soil instrumentation has been always recommended for every preloading project because most of the theories used for consolidation calculations are based on previous empirical efforts. In addition, there are usually many error sources in geotechnical laboratory and field testing, especially in preconsolidation pressure measurements and over-consolidation ratio (OCR) estimates due to soil disturbance. Furthermore, there are some parameters such as horizontal consolidation coefficient or smear zone effects which cannot be measured or evaluated correctly by field or laboratory tests. Therefore, the monitoring results of the preloading projects may exhibit considerable differences with respect to the preliminary analysis and design in estimating the maximum settlements and time of consolidation. Owing to such uncertainties, the use of soil instrumentation has increased in preloading projects. Through instrumentation and monitoring results, the estimated initial settlement, pore water pressure dissipation rate and other applicable quantities can be refined through the back-analysis during the project construction progress and predictions can be fine-tuned.

The consolidation process in low permeable clay deposits is time consuming. Shortening of drainage path is one of the most practical solutions. Vertical sand drains were frequently used in the past, but nowadays prefabricated vertical drains (PVDs) are widely used to accelerate the consolidation process of soft soils. 
There are many researches in different aspects of consolidation. For example, Terzaghi (1943) proposed the first theory for one-dimensional consolidation of clay. Gibson et al. (1967) studied finite non-linear consolidation of thin homogeneous layers and Asaoka (1978) presented an observation procedure for settlement prediction. The hyperbolic method, as another method to predict the maximum settlement was also proposed for the consolidation analysis (e.g. Sridharan \& Sreepada 1981; Sridharan et al. 1987; Tan 1995).

Basu and Prezzi (2009) focused on the effects of soil disturbance on design of PVDs. Rujikiatkamjorn and Indraratna (2009) presented a design procedure for vertical drains based on smear zone effects and lateral permeability. While, Abuel-Naga et al. (2012) provided design curves for preloading with PVDs. Liu and Griffiths (2014) provided a theory for one-dimensional consolidation based on time-dependent changes in the soil stress.

Studies are also available that present numerical modelling and back-analysis of preloading projects with PVDs. Cao et al. (2001) carried out numerical modelling through which they obtained a good prediction of settlement-time curve, but over-predicted the dissipation rate of excess pore pressure owing to neglecting the viscosity effects during consolidation. Arulrajah et al. (2004) investigated the factors affecting the field instrumentation assessment of a marine clay consolidated using PVDs. They stated that the consolidation percentage predicted from piezometer readings is in good agreement with the Asaoka and hyperbolic methods. Indraratna et al. (2005) developed a modified consolidation theory for vertical drains incorporating vacuum preloading and smear effects for both axisymmetric and plane strain conditions. Shen et al. (2005) discovered that the field soil hydraulic conductivity is around six times of the laboratory test values for soft clay based on their FEM back-analysis. Chai and Hayashi (2006) indicated that vacuum pressures apply an isotropic consolidation condition to the sample and cause less settlement than the equivalent surcharge loads. Basu et al. (2007) showed that the transition zone has a considerable impact in slowing down the consolidation process, and therefore, must be considered in design.

In terms of recent researches, Rujikiatkamjorn et al. (2008) presented 2D and 3D numerical modellings of combined surcharge and vacuum preloading with PVDs. They demonstrated that the results of 2D and 3D analyses in vertical and horizontal deformations and induced excess pore pressures were very similar to each other, and hence 2D analysis would be sufficient for practical applications. Bhosle and Vaishampayan (2009) showed that Plate settlement instruments are more reliable than the magnetic extensometers for marine clay. Wu and Hu (2012) provided an improved analytical model for vacuum preloading with PVD. Fakharian and Mehdizadeh (2015) showed that if consolidation parameters are determined adequately, especially OCR, the conventional theories could provide reasonable estimates of the settlements and consolidation time.

The Special Economic Petrochemical Zone (PetZone) of Mahshahr required storing the Karun River water for petrochemical industries in PetZone. Four water tanks needed to be constructed in northwest of Sarbandar City in the Kuzestan Province to collect the Karun River water. Two concrete tanks, $150 \times 100 \mathrm{~m}$ each, with a maximum applied pressure of $100 \mathrm{kPa}$ were considered. Based on geotechnical investigation results, preloading with PVDs was selected for ground improvement of this project.

Considering the tanks structure and sealing system sensitivity to non-uniform settlements, instrumentation of the preloading process was very important and the client agreed to a widespread instrumentation plan to monitor the deformations and excess pore pressures in different soil layers. Surface settlement monuments, magnetic extensometers, vibrating wire (VPZ) and Casagrande (CPZ) piezometers, thermistors and inclinometers were used to monitor the project. This paper evaluates and compares the instrumentation results of both tanks (Tanks No. 3 and 4) for a duration of more than one year during backfilling and afterwards. Maximum settlements are predicted using the hyperbolic and Asaoka methods and a few suggestions are provided for soil instrumentation installation and result interpretation. 


\section{Methodology}

Geotechnical investigation, soil classification and construction plan are the main elements of every preloading project. Having known the soil characteristics, the length, spacing, layout and type of vertical drains can be estimated. Construction sequences and operations usually interfere with and hence affect consolidation settlements, installation of instruments and the reading plan.

Mahshahr Port is located in the tidal zone in the northwest corner of the Persian Gulf. The geotechnical investigation indicated that there are three different layers and engineering properties of two layers gradually increase with depth. The first layer is cohesive clay with sand and silt lenses at different levels. This starts from the surface and continues down to approximately $15 \mathrm{~m}$. This layer is very sensitive to consolidation and is expected to settle significantly during preloading. The second layer is cohesion less silty sand, starting from $15 \mathrm{~m}$ and continuing to $22 \mathrm{~m}$. Sublayers of lean clay with low thickness have been observed as well. The third layer is again cohesive lean clay within which the consistency changes from stiff to hard, starting from $22 \mathrm{~m}$ and continuing to the end of boreholes. The hydraulic conductivity of the first layer varies between $10^{-6}$ to $10^{-10} \mathrm{~m} / \mathrm{s}$. Table 1 presents the geotechnical data for soil layers and Figure 1 shows the SPT profile of the entire site. It is worth noting that water table is observed to be $1 \mathrm{~m}$ below the ground surface.

Table 1 Geotechnical properties of soil layers

\begin{tabular}{ccccc}
\hline Parameter & Unit & Layer I & Layer II & Layer III \\
\hline Classification (USCS) & - & $\mathrm{CL}$ & $\mathrm{SM}, \mathrm{ML}$ & $\mathrm{CL}, \mathrm{ML}-\mathrm{CL}$ \\
Total unit weight & $\mathrm{kN} / \mathrm{m}^{3}$ & $19.5-20.5$ & $19.5-21$ & $20-21$ \\
Moisture content & $\%$ & $25-30$ & $24-25$ & 23 \\
Undrained cohesion & $\mathrm{kPa}$ & $30-45$ & - & 150 \\
$\quad$ Liquid limit & $\%$ & $34-40$ & - & 40 \\
Plasticity index & $\%$ & $15-18$ & - & 23 \\
OCR & & $1-1.8$ & - & - \\
Modulus of elasticity & $\mathrm{kPa}$ & $10-13$ & $22-30$ & $>40$ \\
Undrained Poisson's ratio & - & $0.45-0.5$ & 0.35 & 0.4
\end{tabular}

${ }^{1}$ OCR calculated from the odometer test results.

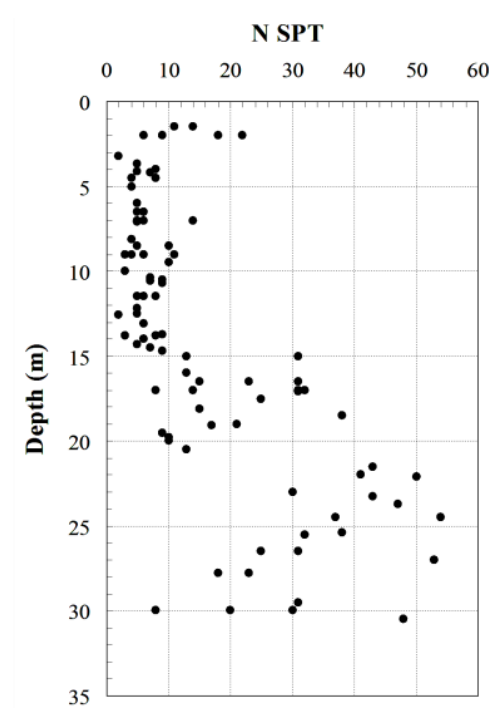

Figure 1 SPT blow count profile with depth 
Based on the geotechnical investigation, the first layer needed to be consolidated before the construction of tanks. A mixture of sand and gravel with a density equal to $17 \mathrm{kN} / \mathrm{m}^{3}$ was selected for the embankments. The heights of the embankments were 7.5 and $8 \mathrm{~m}$ for Tanks No. 3 and 4, respectively, which were 30 and $35 \%$ more than the water tank pressure in full condition. A drainage blanket with $0.5 \mathrm{~m}$ thickness was prepared before filling to improve hydraulic performance and discharge capacity of PVDs.

The embankment of Tank No. 4 was constructed in 57 days. However, due to execution and economic problems, construction of another embankment took around 300 days. Figure 2 shows the position of the two tanks next to each other at the end of filling of embankment No. 4 and during installation of PVDs for Tank No. 3.

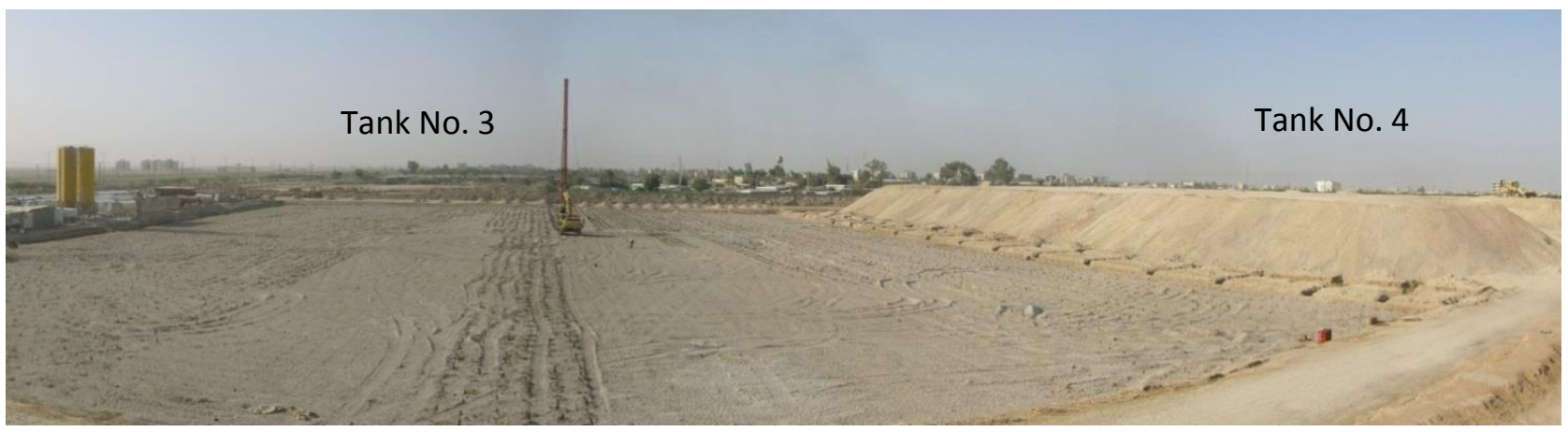

\section{Figure 2 Position of two water tanks}

\section{Data}

The main object of field instrumentation of the preloading project was measuring of vertical and horizontal deformations and induced excess pore pressure. Overall, 48 vibrating wire and 16 Casagrande piezometers, two inclinometers, five thermistors, eight magnetic extensometers and 30 surface settlement monuments were used at different depths and levels for both tanks.

Vibrating wire piezometers were installed at depths of $4,6,8,10,12$ and $14 \mathrm{~m}$ below the surface. The filters of Casagrande piezometers were installed at different depths from 2 to $13 \mathrm{~m}$ below the surface. To protect the vibrating wire piezometers, they were placed inside the reticulated PVC tubes before installation and filled with sand soil. Figure 3 shows the protective tubes for vibrating wire piezometers. These supporting tubes were used for protecting the Casagrande filters as well, but they were made of stainless steel. The surrounding voids of piezometers up to the surface were filled with bentonite-cement mixture according to the manufacturer's procedure.

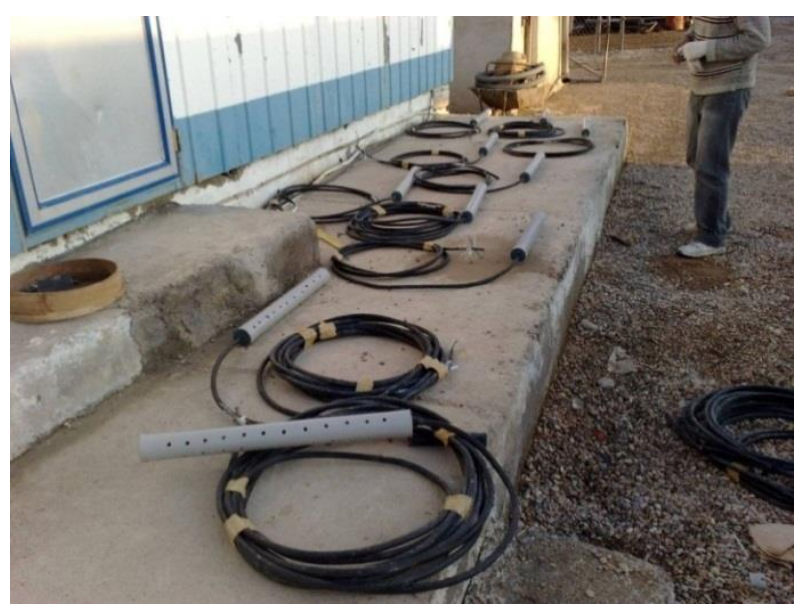

\section{Figure 3 Protective PVC tubes for vibrating wire piezometers}

The distance between the spiders of the magnetic extensometers was $3 \mathrm{~m}$ and the soil layers settlements were measured down to $-25 \mathrm{~m}$. Ground surface elevation was $+4.00 \mathrm{~m}$ and the elevations of the beginning 
of the second and third layers were around -11.00 and $-17.00 \mathrm{~m}$. Five thermistors were installed at the centre of Tank No. 4 at depths of 5, 10, 15, 20 and $25 \mathrm{~m}$ below the surface to investigate the effects of variation of earth temperature on water viscosity in different seasons. Figure 4 presents the instrumentation layout in the centre of Tank No. 4.

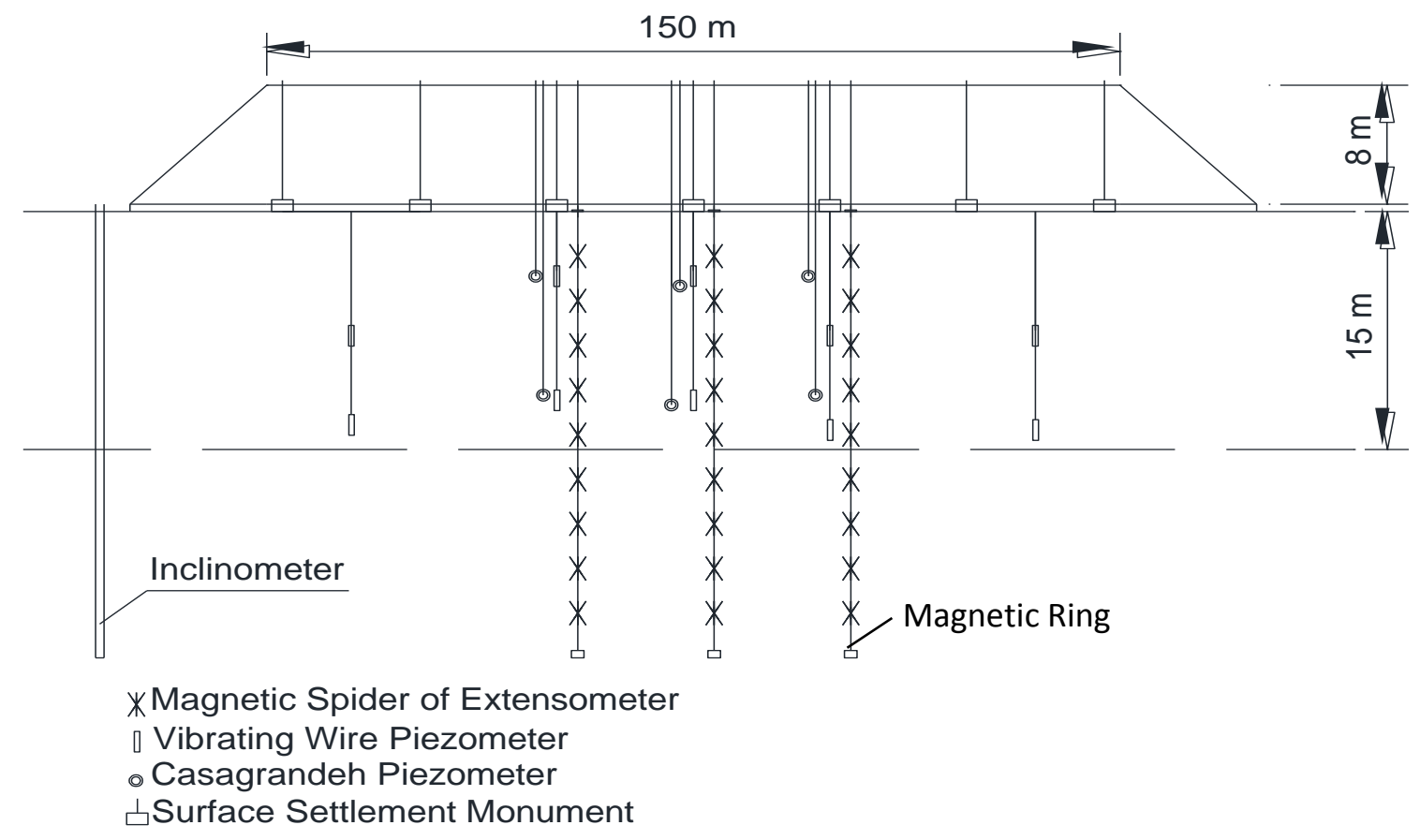

\section{Figure 4 The instrumentation layout at the centre of Tank No. 4}

Based on client requirements and soil properties, PVDs were installed down to $15 \mathrm{~m}$ with $1.5 \mathrm{~m}$ spacing in a triangular pattern for both tanks. Mandrel, PVDs and design parameters are illustrated in Table 2. Soft clay soils in Mahshahr are usually known as normally consolidated (NC) or slightly over-consolidated (OC) clay. Based on one-dimensional consolidation theory, the required time for $90 \%$ of consolidation is calculated to be around 12 years. Immediate settlement (elastic settlement) and consolidation settlement of Layer I were estimated as 200 and $780 \mathrm{~mm}$ for NC clay with an elastic modulus of $10 \mathrm{MPa}$ and $136 \mathrm{kPa}$ surcharge.

\section{Table 2 PVD, mandrel and design parameters}

\begin{tabular}{|c|c|c|c|c|c|c|c|c|}
\hline \multicolumn{3}{|c|}{ PVD dimensions } & \multicolumn{3}{|c|}{ Mandrel dimensions } & \multicolumn{3}{|c|}{ Design parameters } \\
\hline $\begin{array}{c}a \\
(\mathrm{~mm})\end{array}$ & $\begin{array}{c}b \\
(\mathrm{~mm})\end{array}$ & $\begin{array}{c}d_{w} \\
(\mathrm{~mm})\end{array}$ & $\begin{array}{c}w \\
(\mathrm{~mm})\end{array}$ & $\begin{array}{c}I \\
(\mathrm{~mm})\end{array}$ & $\begin{array}{c}d_{m} \\
(\mathrm{~mm})\end{array}$ & $\begin{array}{c}C_{h} \\
\mathrm{~m}^{2} / \mathrm{y}\end{array}$ & $\begin{array}{c}S \\
(\mathrm{~m})\end{array}$ & $\begin{array}{l}D_{e} \\
(\mathrm{~m})\end{array}$ \\
\hline 100 & 3.5 & 0.066 & 72 & 142 & 0.114 & 3.8 & 1.5 & 1.575 \\
\hline
\end{tabular}

where:

$a$ is the width of PVD, $b$ is the thickness of PVD, $d_{w}$ is the diameter of equivalent circle of PVD, $w$ is the width of mandrel, $I$ is the thickness of mandrel, $d_{m}$ is the diameter of mandrel, $C_{h}$ is the horizontal consolidation coefficient, $S$ is the PVD spacing and $D_{e}$ is the effective diameter of drainage of PVD.

\section{$4 \quad$ Results}

Any soil instrumentation includes instruments selection, providing best instruments layout to cover all project requirements, calibration, zero reading, installation, periodic reading and interpretation. In this project, periodic readings were performed every two weeks until the end of filling to check the stability of 
embankments on soft soil. Then, the time interval increased regarding variations of settlements and dissipation of excess pore pressures.

\subsection{Instruments results}

The average of ground surface settlements measured by surface monuments and magnetic extensometers of Tanks No. 3 and 4 are presented in Figure 5. The trend of both graphs is similar for the first 30 days but with change in loading rate, the soil behaved differently beneath the two embankments. Although the graphs of settlements show a different pattern due to different rates of loading, the rate of settlements starts to decrease after the end of filling for both tanks.

The maximum surcharge applied to Tanks No. 3 and No. 4 was 127 and $136 \mathrm{kPa}$, respectively, which shows $8 \%$ difference. Maximum settlement for Tank No. 4 reached $750 \mathrm{~mm}$ after 320 days, which can be assumed as the final consolidation settlement including the settlements of Layer I, while it was $604 \mathrm{~mm}$ for Tank No. 3 after 440 days. It is worth noting that the filling for Tanks No. 3 and 4 took around 310 and 57 days, respectively.

Although the length and layout of PVDs are similar for both tanks, Tanks No. 3 and 4 experienced 69 and $50 \%$ maximum consolidation settlements, respectively, at the end of filling. This happened due to the different elapsed time for embankment construction for two tanks. On the other hand, for an interval time of approximately 130 days after filling, 11\% maximum settlement occurred in Tank No. 3 which was much less than the $42 \%$ in Tank No. 4 . This is also obvious from the slopes of the two graphs after the end of filling.

The authors think that the clogging phenomenon and bending effects owing to loading reduced the lifetime of the PVDs and therefore it is not expected that the settlement in Tank No. 3 would reach the same maximum at Tank No. 4 during the 260 days after filling. The decreasing rate of settlement after the end of filling in Tank No. 3 confirmed this assumption. Also, Mahshahr city is located in a region with severe monsoon rains which change the water table level annually and this can affect the PVDs and preloading responses due to the long filling period. The effect of such raining observed in piezometers results which discussed later.

Although just $80 \%$ consolidation occurred after 440 days in Tank No. 3, the preloading was successful due to increased surcharge to 1.3 of the design load. It is worth mentioning that if the preloading surcharge exceeds the design load by $30-35 \%, 100 \%$ of the required settlements could occur in a consolidation time corresponding to $80-85 \%$.

In addition, as shown in Figure 5, $23 \mathrm{~mm}$ heave was observed at the end of consolidation of Tank No. 4, which was related to the removal of $3 \mathrm{~m}$ embankment materials for backfilling of the surrounding area. This $23 \mathrm{~mm}$ heave can be evaluated as elastic settlement. Preloading cannot eliminate elastic settlement, however, it increases the modulus of elasticity and therefore reduces immediate settlements during service lifetime of the structures. The improved modulus of elasticity can be calculated by back-analysis.

Magnetic extensometers were used to measure the subsoil layers settlement. Figure 6 shows the results of magnetic extensometers in the centre of each tank for one of the first readings and the last reading. Ground surface elevation is $+4.00 \mathrm{~m}$ and the second layer starts from an elevation of -11.00 , equal to $15 \mathrm{~m}$. The position of spiders and bottom rings was evaluated by surveying of top of the extensometer tubes.

As expected, most of the settlements that are equal to $72 \%$ of total settlement are attributed to the upper $15 \mathrm{~m}$. Immediate and consolidation settlements of Layers II and III are approximately 15 and $13 \%$ of total settlements. As seen in Figure 6, although the maximum settlement of both tanks is different, Layers II and III showed similar settlement and trends beneath Tanks No. 3 and 4. However, there was an attempt to put the bottom of the magnetic extensometers and inclinometers in an elevation which not be affected by loading; their results revealed that loading impacts spread down to more than $30 \mathrm{~m}$ and moved the bottom of the instruments but this impact was considered in the analysis. 


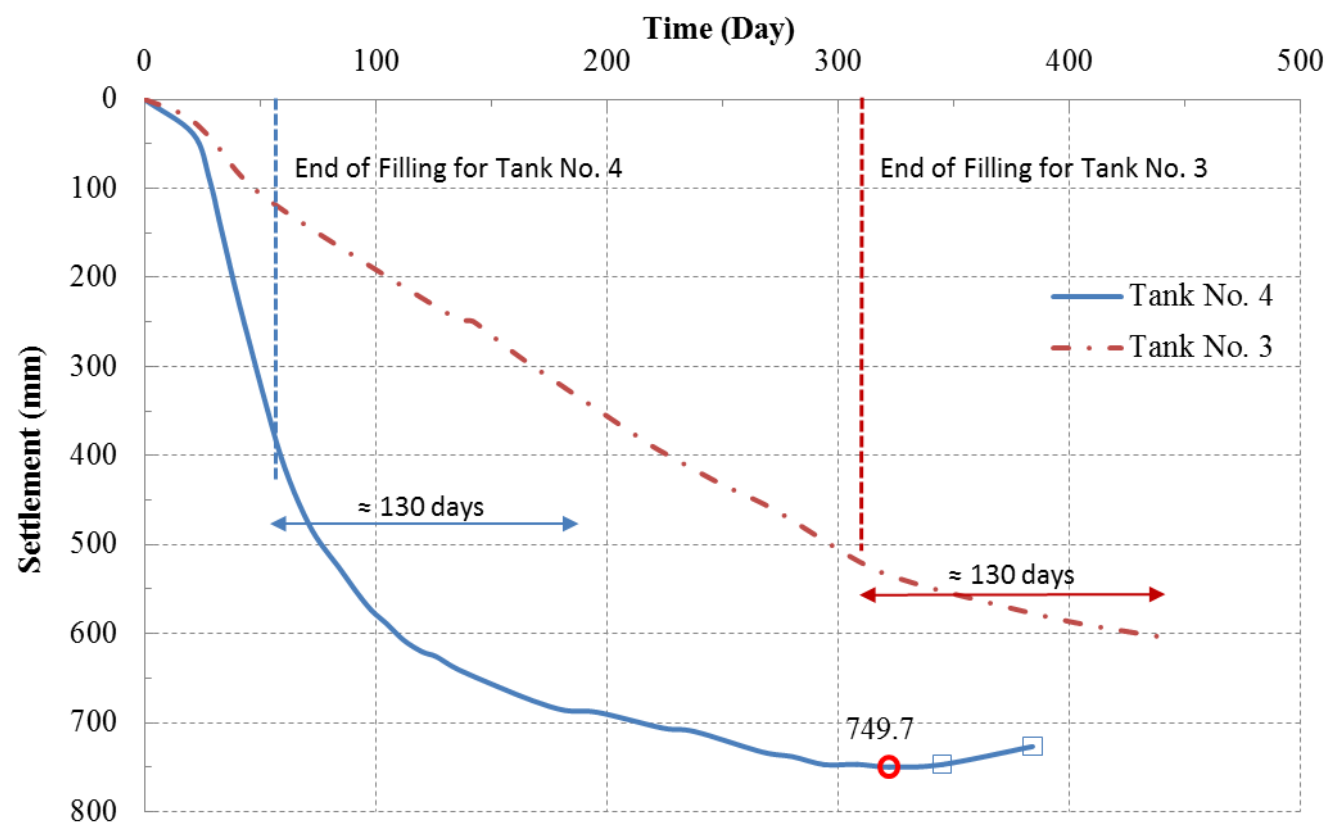

Figure 5 Surface settlements against time for Tanks No. 3 and 4
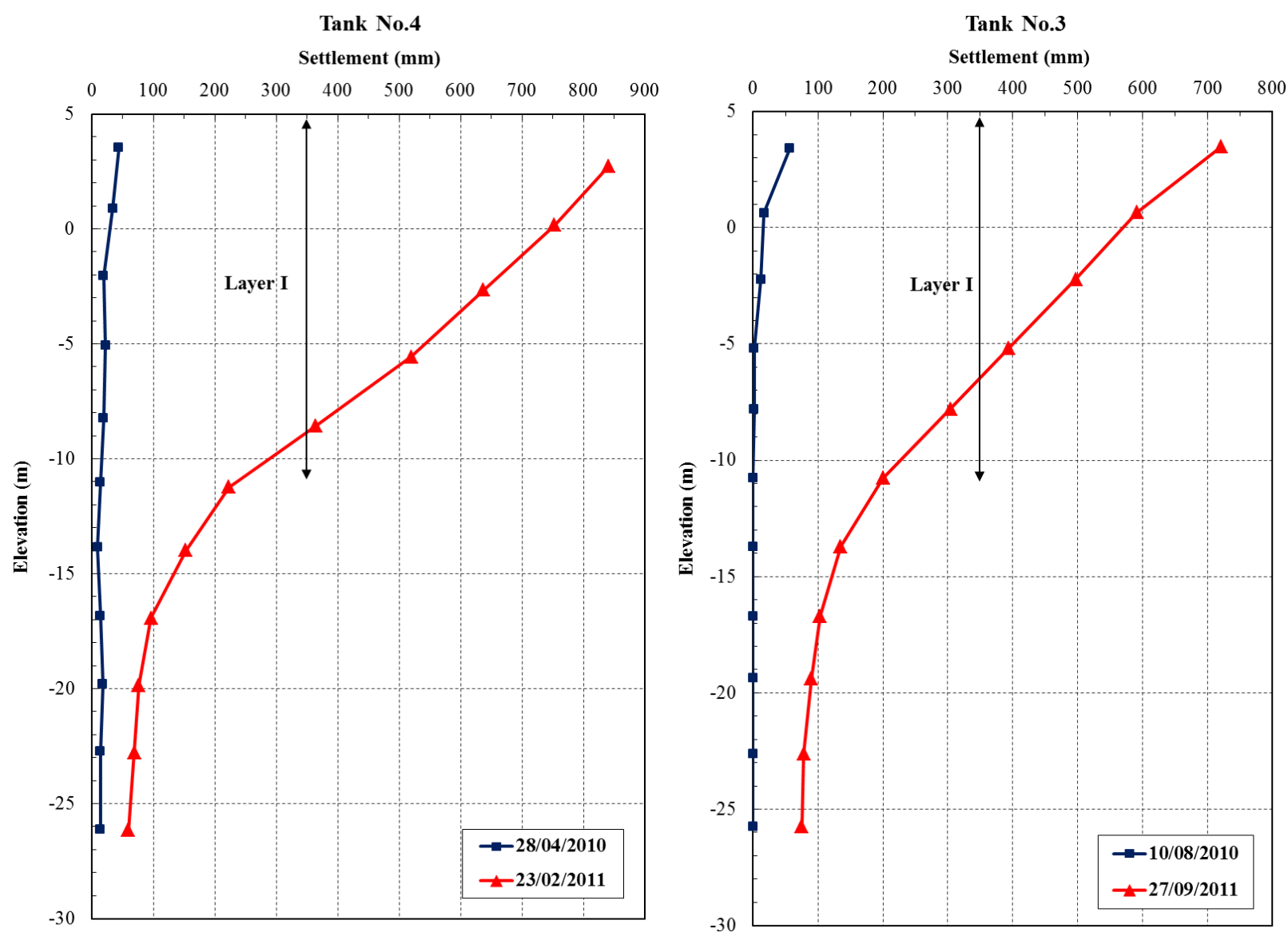

Figure 6 Magnetic extensometers results at the centre of Tanks No. 3 and 4

It is worth noting that Figure 6 shows the settlements in the centre of Tanks, but Figure 5 presents the average of maximum settlement throughout each tank.

Other instruments which used thoroughly were vibrating wire and Casagrande piezometers. In the centre of Tank No. 4, two vibrating wire piezometers at depths of 4 and $12 \mathrm{~m}$ and two Casagrande piezometers in 
depths of 5 and $13 \mathrm{~m}$ were installed. For Tank No. 3, vibrating wires piezometers were installed at depths of $4,8,10,12$, and $14 \mathrm{~m}$ and Casagrande piezometers were installed at depths of 4 and $12 \mathrm{~m}$.

The piezometers which were installed in Tank No. 4 measured induced excess pore pressures much better than those in the other tank because the rate of loading was high enough to prevent the EPPs dissipating quickly.

Figure 7 shows the results of installed piezometers in the centre of each tank against time and according to embankment height. In Tank No. 4, every filling stage corresponds with a jump in excess pore pressure curves in vibrating wire Piezometers. Such jumps cannot be seen in the Casagrande piezometers due to their inherent time lag. But they increased clearly until the end of filling. None of the piezometers installed in Tank No. 3 showed considerable increase due to low rate of filling.

The piezometers installed at a depth of $4 \mathrm{~m}$ in both tanks did not measure any noticeable EPP during filling. This may be owing to over-consolidation of soil layers near to the surface or the short distance between piezometers and the drainage blanket.

Another point is that the vibrating wire piezometers in Tank No. 3 stabilised at a new level that was higher than the initial reading, unlike the piezometers in Tank No. 4. Although the settlements did not reach the desired maximum magnitudes, the piezometers show a steady state after 400 days. The question is: if $100 \%$ of consolidation does not occur, why do the total excess pore pressures dissipate? The authors think that, as was mentioned previously, by increasing the time of filling and taking into account the fall and winter precipitation, the water table and excess pore pressure reached a new stable state and therefore the piezometer results could not be interpreted based on previous measurements. Also like PVDs, the clogging phenomenon may happen in the filter of piezometers after a long time, which prevents them from working correctly.

A slight increase of excess pore pressure was observed at the end of consolidation which was probably related to the removing of $3 \mathrm{~m}$ of surcharge for back filling of the surrounding area. This pressure released after a few days.

To summarise, instrumentation results clarified that the piezometers which were installed at a depth of 8 to $12 \mathrm{~m}$ below the surface were more sensitive than the others in Layer I with $15 \mathrm{~m}$ thickness. Also, it is likely that Piezometers installed near PVDs cannot capture the EPP correctly. Therefore, coincidence between dissipation of EPP and constant readings of settlements prove completion of consolidation, but overall, the completion of settlement is a more reliable criterion based on mentioned errors, which may affect the piezometer measurement.

Construction of earth embankment on soft soils in a short period of time needs caution due to risk of soil failure. The formation of any failure can be monitored by induced pore pressures beneath the embankment and horizontal deflections and heaves in the surrounding area. To investigate horizontal deformations, two inclinometers were installed as illustrated in Figure 4. The inclinometer results showed that maximum horizontal deformations reached 28 and $41 \mathrm{~mm}$ toward the embankments, respectively.

To measure the variation of temperature inside the soil and investigate its effects on water viscosity, five vibrating wire thermistors were installed at the centre of Tank No. 4 at depths of 5, 10, 15, 20 and $25 \mathrm{~m}$. Although yearly fluctuation of temperature is considerable in Port Mahshahr, the measured data of thermistors showed no change in soil temperature during the day or night or in different seasons. The temperature of soil steadily maintained $30,30,33,29$ and $28^{\circ} \mathrm{C}$ at depths of $5,10,15,20$ and $25 \mathrm{~m}$ below the surface and these variations may be due to their calibrations. Therefore, it seems the soil temperature was always around $30^{\circ} \mathrm{C}$ regardless of season. 

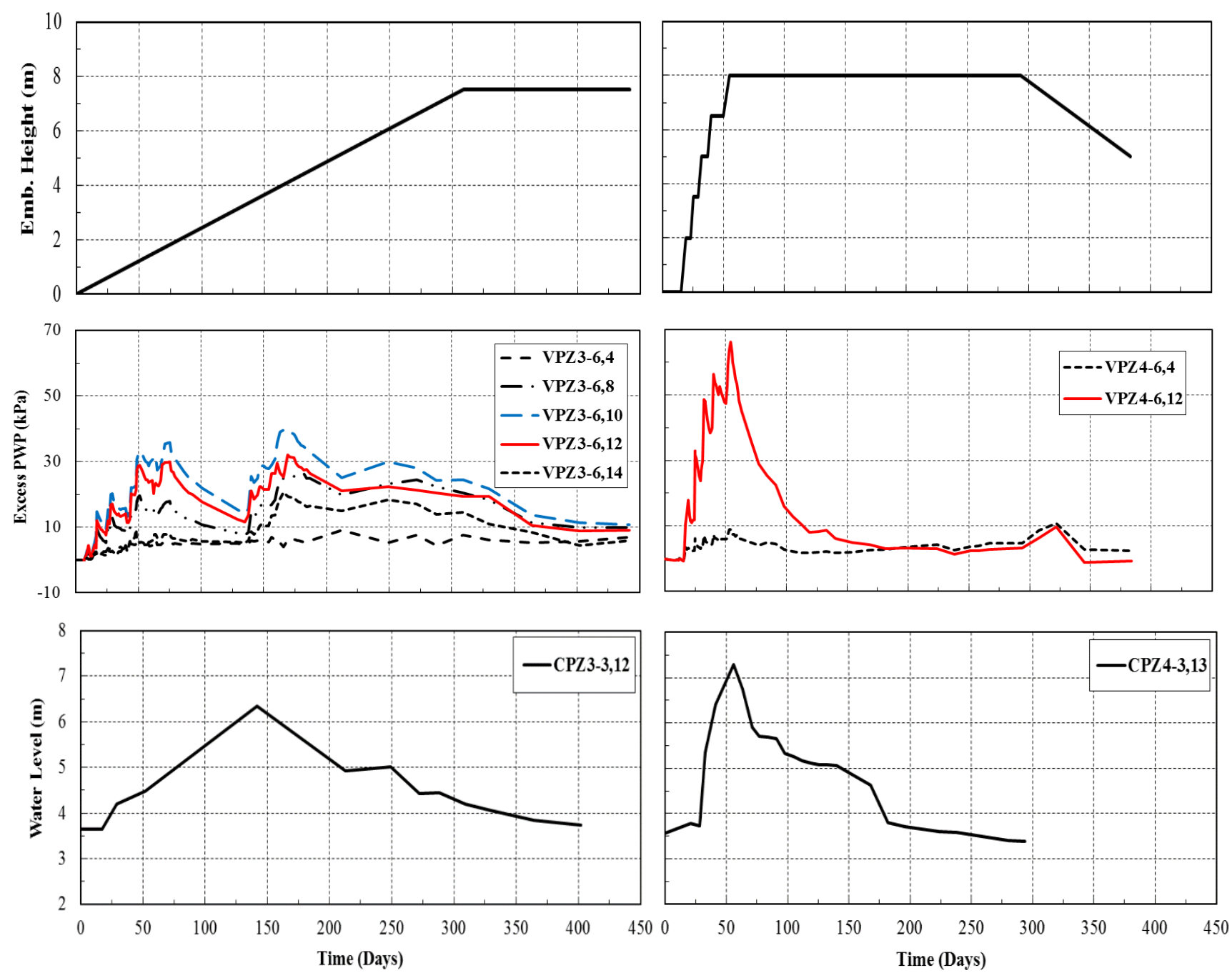

Figure 7 Vibrating wire and Casagrande piezometers results at the centre: Tank No. 3 (left); and 4 (right) against time and embankment height

\subsection{Back-analysis}

According to preliminary design, maximum immediate and consolidation settlement should be around 200 and $780 \mathrm{~mm}$, respectively, and 12 years are required for $90 \%$ consolidation to occur. The average measured settlement in Tank No. 4 showed that maximum settlement of Layer I including immediate and consolidation reached $540 \mathrm{~mm}$ in 322 days and $90 \%$ consolidation occurred in just 168 days. The contributions of vertical and horizontal consolidation are 20 and $87 \%$, respectively, for $90 \%$ consolidation.

An equation which was developed by (Hansbo 1979) for estimation of time of consolidation when vertical drains are used showed that the required time for $87 \%$ horizontal consolidation is 147 days regardless of smear effects and well resistance. The instrument results revealed that the primary design should be reassessed for hydraulic conductivity of smear zone, variations of OCR, horizontal consolidation coefficient and modulus of elasticity, which affect the soil consolidation time and settlement. Fakharian and Mehdizadeh (2015) refined the design parameters for Tank No. 4 by back-analysis and the Asaoka method.

This paper used the hyperbolic method as another method for predicting the maximum consolidation settlement under combined vertical and radial drainage. As mentioned, this method was developed by different researchers. The hyperbolic method developed by Tan (1995) was selected to predict the maximum settlement of Tank No. 4 in this research. 
Tan (1995) provided a procedure for using the hyperbolic method. The first step is plotting the hyperbolic form of the field settlement data as $t / \delta$ versus $t$ from the end of filling, identifying the first linear segment and measuring its slope $\left(\mathrm{S}_{\mathrm{i}}\right)$ (Figure 8 ).

The next step is determining the theoretical value of the initial linear slope $(\alpha)$ based on $H / D, D_{e} / d_{w}$ and $C_{h} / C_{v}$. ( $H$ is vertical drainage path length and $C_{v}$ is vertical consolidation coefficient). Fakharian and Mehdizadeh found that $C_{h} / C_{v}$ should be around 1 for this site by back-analysis. $\alpha$ was determined to be equal to 0.77 according to the graph provided by Tan (1995).

The last step is calculating the slope of the lines radiating from the origin, intercepting the 60 and $90 \%$ consolidation points and constructing them in a hyperbolic plot by Equations 1 and 2 .

$$
\begin{aligned}
& \mathrm{S}_{60}:(1 / 0.6)\left(\mathrm{S}_{\mathrm{i}} / \alpha\right) \\
& \mathrm{S}_{90}:(1 / 0.9)\left(\mathrm{S}_{\mathrm{i}} / \alpha\right)
\end{aligned}
$$

where:

$S_{60}$ and $S_{90}$ are the slopes of the lines from the origin to the 60 and $90 \%$ consolidation points, respectively.

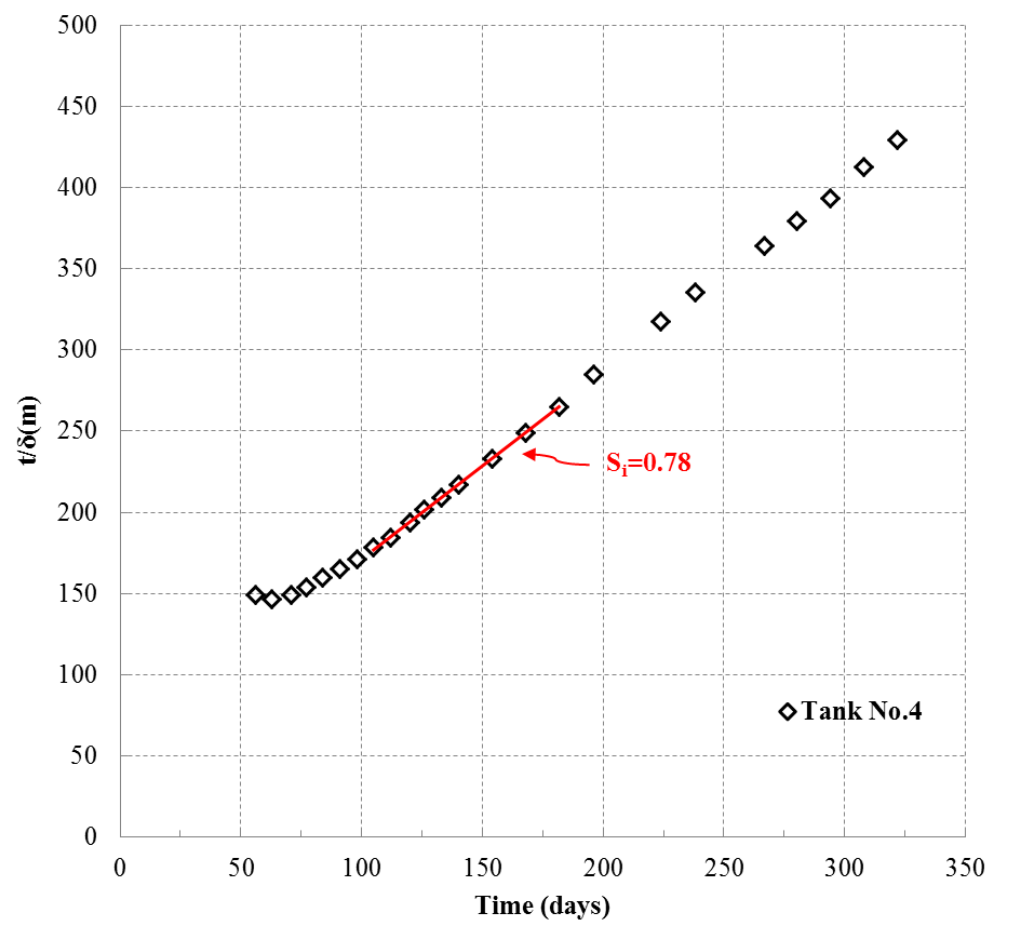

Figure 8 Hyperbolic plot for settlements instruments results in Tank No. 4

The predicted maximum settlements based on the hyperbolic and Asaoka methods which were determined by Fakharian and Mehdizadeh (2015) are shown in Table 3.

Table 3 Predicted maximum settlement by the hyperbolic and Asaoka methods for Tank No. 4

\begin{tabular}{ccccccc}
\hline$\alpha / S_{i}$ & $\delta_{60} / 0.6$ & $\delta_{90} / 0.9$ & $\begin{array}{c}U_{70} \\
\text { Asaoka }\end{array}$ & $\begin{array}{c}U_{80} \\
\text { Asaoka }\end{array}$ & $\begin{array}{c}U_{90} \\
\text { Asaoka }\end{array}$ & $\begin{array}{c}\mathrm{S}_{\max } \\
\text { observed }\end{array}$ \\
\hline $987 \mathrm{~mm}$ & $589 \mathrm{~mm}$ & - & $844 \mathrm{~mm}$ & $761 \mathrm{~mm}$ & $759 \mathrm{~mm}$ & $750 \mathrm{~mm}$ \\
\hline
\end{tabular}

The line with a slope of $S_{90}$ did not intercept the hyperbolic plot. Table 3 shows that the Asaoka method predicted maximum settlement better than the hyperbolic method for soft soil of this project, but $80 \%$ consolidation should have occurred. 


\section{Conclusion}

The results of an instrumented preloading project for ground improvement of two water tanks in southwest of Iran are presented and the results are discussed. The instruments results were presented and compared in both tanks and the maximum settlements predicted by the hyperbolic method were compared with the Asaoka method. Based on the presented results, the following conclusions are made:

Magnetic extensometers measured settlements slightly higher than surface settlement monuments, but the trend of all settlement instruments showed very good agreement with each other.

Service time of PVDs and instruments must be considered in the required time of preloading projects. Clogging phenomena may affect the discharge capacity of PVDs or performance of piezometers.

Variations of ground water table during different seasons may have some impact on piezometer results, and therefore, they cannot capture the dissipation of excess pore pressure accurately.

The piezometers installed $4 \mathrm{~m}$ below the drainage blanket did not sense considerable excess pore pressure. The over-consolidation of upper layers near to the surface or the short distance between piezometer and drainage blanket may have contributed to this observation.

The piezometers installed in the middle third of soft soil showed the best performance with respect to other elevations.

In this project the Asaoka method predicted the maximum settlement of the soft soil better than the hyperbolic method.

\section{Acknowledgement}

The authors thank the Engineering Department of Special Economic Petrochemical Zone (PetZone) of Mahshahr for providing their facilities and financial support and Tehran-Boston Co. and Pars GeoEnviro Co. for providing the technical information to perform this project.

\section{References}

Abuel-Naga, HM, Pender, MJ \& Bergado, DT 2012, 'Design curves of prefabricated vertical drains including smear and transition zones effects', Geotextiles and Geomembranes, vol. 32, pp. 1-9.

Arulrajah, A, Nikraz, H \& Bo, MW 2004, 'Factors affecting field instrumentation assessment of marine clay treated with prefabricated vertical drains', Geotextiles and Geomembranes, vol. 22, pp. 415-437.

Asaoka, A 1978, 'Observation procedure of settlement prediction', Soils and Foundation, vol. 18, no. 4, pp. 89-101.

Basu, D \& Prezzi, M 2009, 'Design of prefabricated vertical drains considering soil disturbance', Geosynthetics International, vol. 16, no. 3, pp. 147-157.

Basu, D, Basu, P \& Prezzi, M 2007, 'Analytical solutions for consolidation aided by vertical drains', Geomechanics and Geoengineering: An International Journal, vol. 1, no. 1, pp. 63-71.

Bhosle, P \& Vaishampayan, VV 2009, 'Case study for ground improvement using PVD with preloading for coal and iron ore stackyard', Proceedings of the Annual Conference of the Indian Geotechnical Society, pp. 506-509.

Cao, LF, Chang, M, Teh, Cl \& Na, YM 2001, 'Back-calculation of consolidation parameters from field measurements at a reclamation site', Canadian Geotechnical Journal, vol. 38, no. 4, pp. 755-769.

Chai, JC \& Hayashi, S 2006, 'Characteristics of vacuum consolidation', Proceedings of the 16th International Conference on Soil Mechanics and Geotechnical Engineering, Millpress, Rotterdam.

Fakharian, K \& Mehdizadeh, A 2015, 'Investigation of field instrumentation in a preloading project', Proceedings of the Institution of Civil Engineers Geotechnical Engineering, vol. 168, no. 1, pp. 87-98.

Gibson, RE, England, GL \& Hussey, MJL 1967 'The theory of one dimensional consolidation of saturated clays, 1: finite non-linear consolidation of thin homogeneous layers', Geotechnique, vol. 17, no. 3, pp. 261-273.

Hansbo S 1979, 'Consolidation of clay by band-shaped prefabricated drains', Journal of Ground Engineering, vol. 12, no. 5, pp. 16-25.

Indraratna, B, Sathananthan, I, Rujikiatkamjorn, C \& Balasubramaniam, AS 2005, 'Analytical and numerical modelling of soft soil stabilized by prefabricated vertical drains incorporating vacuum preloading', International Journal of Geomechanics, vol. 5, no. 2, pp. 114-124.

Liu, JC \& Griffiths, DV 2014, 'A general solution for 1D consolidation induced by depth- and time-dependent changes in stress', Geotechnique, vol. 10, no. 1, pp. 1-7. 
Rujikiatkamjorn, C \& Indraratna, B 2009, 'Design procedure for vertical drains considering a linear variation of lateral permeability within the smear zone', Canadian Geotechnical Journal, vol. 46, no. 3, pp. 270-280.

Rujikiatkamjorn, C, Indraratna, B \& Chu, J 2008, '2D and 3D numerical modelling of combined surcharge and vacuum preloading with vertical drains', International Journal of Geomechanics, vol. 8, no. 2, pp. 144-156.

Shen, S, Chai, J, Hong, Z \& Cai, F 2005, 'Analysis of field performance of embankments on soft clay deposit with and without PVD-improvement', Geotextiles and Geomembranes, vol. 23, pp. 463-485.

Sridharan, A \& Sreepada, RA 1981, 'Rectangular hyperbola fitting method for one-dimensional consolidation', Geotechnical Testing Journal, vol. 4, no. 4, pp. 161-168.

Sridharan, A, Murthy, NS \& Prakash, K 1987, 'Rectangular hyperbola method of consolidation analysis', Geotechnique, vol. 37, no. 3, pp. 355-368.

Tan, SA 1995, 'Validation of hyperbolic method for settlement in clays with vertical drains', Soils and Foundation, vol. 35, no. 1, pp. 101-113.

Terzaghi, K 1943, Theoretical soil mechanics, John Wiley \& Sons, New York.

Wu, H \& Hu, L 2012, 'Analytical and numerical solutions for vacuum preloading considering a radius related strain distribution', Mechanics Research Communications, vol. 44, pp. 9-14. 